\title{
A abordagem Pikler-Loczy e a perspectiva histórico-cultural: a criança pequenininha como sujeito nas relações
}

\author{
Suely Amaral Mello* \\ Renata Aparecida Dezo Singulani**
}

\section{Resumo}

A compreensão de que o desenvolvimento humano procede das experiências de vida e educação nos remete a buscar maneiras de promover esse desenvolvimento. À medida que se estuda a teoria histórico-cultural, percebe-se a complexidade desse processo que envolve a formaçáo da personalidade humana desde os primeiros contatos da criança com o mundo que a rodeia. Ao mesmo tempo, profissionais e pesquisadores da educação infantil procuram compreender como se dá esse processo quando as crianças são ainda pequenininhas. Percebe-se na teoria histórico cultural um conjunto de diretrizes que orientam a produção de uma nova prática possível com os pequenininhos que, de um modo geral, sem que se compreenda a complexidade desse processo, são tratados como objetos do trabalho dos adultos e não como sujeitos em formação a partir das experiências que vivem. Quando se pensa nas características das práticas que podem surgir dessas diretrizes teóricas, pensa-se no trabalho desenvolvido pelo Instituto PiklerLoczy e considera-se que as práticas aí desenvolvidas podem mediar a concretização das diretrizes da teoria histórico-cultural. É disso que trata este artigo. Com ele busca-se uma aproximação entre as práticas de educação das crianças pequenininhas criadas naquele instituto, na Hungria, a partir dos anos 1940 e a teoria desenvolvida por Vygotsky e seus colaboradores a partir dos anos 1920, na então União Soviética. A perspectiva é buscar elementos mediadores que concretizem a teoria, de modo que a apropriação dessa abordagem sócio-histórica do desenvolvimento humano se concretize desde a educação dos pequenininhos.

Palavras-chave: Educação Infantil. Relação Teoria-Prática. Teoria Sócio-HistóricoCultural.

\footnotetext{
* Doutorado em Educação pela Universidade Federal de São Carlos (UFSCar). Professora da Pós-Graduação em Educaçáo na Universidade Estadual Paulista Júlio de Mesquita Filho (UNESP).

** Mestre em Educação pela Universidade Estadual Paulista Júlio de Mesquita Filho (UNESP).

Coordenadora pedagógica das creches na cidade de Santa Cruz do Rio Pardo, São Paulo.
} 


\section{Introdução}

Numa análise feita à distância considerando uma experiência de cuidado e educação de crianças pequenas realizada na Hungria a partir dos anos 1940 e uma teoria sobre o desenvolvimento humano sendo produzida na União Soviética desde os anos 1920, poderíamos considerar quejá haveria uma aproximaçáo dada entre a teoria soviética e a prática húngara, fosse pela proximidade geográfica, fosse pelo contexto político envolvendo o leste europeu nesse período. No entanto, a análise da situaçáo vivida pela Hungria até o final dos anos 1980 explica a desconsideração da teoria histórico-cultural por educadores húngaros naquele momento histórico: sofrendo sob as invasôes, primeiro, da Alemanha nazista e, em seguida, da Uniâo Soviética, era natural que os húngaros negassem tudo o que tivesse origem naquela região. $\mathrm{E}$ assim aconteceu. Num momento inicial de desenvolvimento da abordagem educativa, que ficou conhecida como Lóczy, os textos de Vygotsky já haviam se tornado clandestinos devido às perseguições do estalinismo na própria União Soviética. E, a partir dos anos 1990, quando Vygotsky começa ser redescoberto na Rússia, a Hungria tinha razóes para não adotar ideias originadas na Rússia. Por tudo isso, essas aproximaçóes entre as diretrizes da teoria histórico-cultural para a educaçáo do primeiro ano e da primeira infância e as práticas construídas pelo Instituo Pikler-Lóczy não parecem ter sido feitas.

Para nós, estudiosos da teoria histórico-cultural em busca de suas implicaçôes pedagógicas para a educação infantil, é fundamental encontrar práticas que concretizam essa teoria que, ao demonstrar a essencialidade da educação no processo de humanização, aponta a necessidade de uma educação desenvolvente. Por isso, procuramos estabelecer uma relação entre a teoria histórico-cultural e as práticas do Instituto Pikler-Lóczy que favoreça a discussão e a reflexão dos/as professores/as de educaçáo infantil, assim como a dos/as formadores/as desses/as professores/as, destacando as ideias principais que sustentam a compreensão de ser humano e seu desenvolvimento presentes na teoria histórico-cultural e, a partir daí, deflagram uma nova compreensão do papel da educaçáo e da escola, de como se dá o processo de conhecimento, do lugar da criança e do adulto - professor/a - que cuida e educa as crianças nos primeiros três anos de vida.

Com essas ideias, procuramos perceber como elas podem impactar as ideias e intençóes que orientam o agir dos/as professores/as das crianças pequenininhas e como podem impactar suas práticas na perspectiva de uma docência intencionalmente voltada para a formação da personalidade humana desde os primeiros meses de vida. 


\section{A criança pequena como personalidade em formação}

A compreensáo de que a personalidade se forma na vida concreta que cada sujeito vive em sua relação com a cultura mediada pela sociedade - pelo outro - é nova e não foi ainda devidamente apropriada na formação docente. Na escola, de um modo geral, ainda se pensa e se trata a personalidade como própria de cada indivíduo, definida pelas condiçóes genéticas herdadas por cada um.

No entanto, os estudos têm mostrado que, como afirma Leontiev (1978, p. 267): “[... cada indivíduo aprende a ser um homem. O que a natureza lhe dá quando nasce não lhe basta para viver em sociedade. É lhe ainda preciso adquirir o que foi alcançado no decurso do desenvolvimento histórico da sociedade humana”.

Compreender como acontece o processo de formação em cada ser humano das qualidades humanas produzidas "no decurso do desenvolvimento histórico da sociedade" é condiçấo necessária, ainda que não suficiente, para realizar na educação infantil uma docência humanizadora.

Na relação histórica do ser humano com a natureza, esta foi meio e objeto para a confecção e aplicação de instrumentos. Nesse processo, a natureza foi sendo transformada para responder às necessidades humanas, foi sendo humanizada, ou seja, constituída de objetos recipientes da atividade subjetiva. Com isso, o corpo orgânico do ser humano foi se ampliando e constituindo um conjunto de instrumentos que se unem aos órgãos do corpo, prolongando o corpo humano - criando um corpo inorgânico que amplia seu universo de ação, uma vez que afasta as barreiras biológicas que se antepóem ao corpo humano.

Nesse processo de transformação da natureza, portanto, o ser humano também transforma a si próprio e é a "essa dupla transformação, da natureza e dele mesmo, que chamamos de história” (PINO, 2005, p. 30).

Assim, ao se apropriar da natureza e ao se objetivar por meio dela criando objetos e instrumentos, o ser humano cria uma essência que não se encontra dentro dele, mas que é fruto da própria atividade humana sobre a natureza, uma essência que está nas relaçóes e nos objetos - sejam aqueles propriamente ditos, objetivos, sejam os subjetivos. Como afirma Vigotski (2010, p. 695), "o meio desempenha no desenvolvimento da criança, [...] o papel de uma fonte de desenvolvimento”.

Essa essência criada ao longo da história é o gênero humano, aquilo que faz de cada pessoa um ser humano. Sintetizando essa ideia essencial para compreender o processo educativo, podemos destacar que, na relaçáo do ser humano com a natureza, o entorno natural vai se transformando em entorno cultural que guarda em repouso as 
forças humanas essenciais - as qualidades humanas, o corpo inorgânico do homem criadas no mesmo processo em que se cria a cultura, isto é, a natureza transformada. Por isso, para Vigotski (2010), a cultura produzida social e historicamente é a fonte das qualidades humanas, pois em seus objetos "estão incorporadas e fixadas as operaçóes de trabalho historicamente elaboradas" (LEONTIEV, 1978, p. 268), de cuja apropriação depende o processo de humanização das próximas geraçóes humanas.

Então, nos objetos da cultura - na língua, na lógica, nos hábitos e costumes, na ciência, nas formas de sentir e expressar, nos objetos e instrumentos -, o movimento e a energia, as capacidades, as habilidades - as forças humanas essenciais (MARX, 2004) utilizadas no processo de sua criação, apresentam-se estáticos, em repouso, incorporados no objeto produzido pela atividade humana, potencialmente presentes no objeto. Ao reproduzir a função adequada do objeto, um aprendiz reaviva a energia ali posta, criando para si as funções psíquicas superiores (VYGOTSKI, 1995).

Portanto, no processo de apropriação e objetivação da cultura, a pessoa apropria-se do gênero humano - da humanidade formada ao longo da história e existente no nascimento das novas geraçóes. Nesse processo, cria a sua individualidade, faz das objetivaçôes humanas "órgãos da sua individualidade", conforme metáfora utilizada por Marx (2004).

No entanto, a relação com a cultura para a apropriação das qualidades humanas aí em repouso exige uma mediação social, pois conforme Leontiev (1978, p. 268): "Para se apropriar dos objetos e dos fenômenos que são o produto do desenvolvimento histórico, é necessário desenvolver em relação a eles uma atividade que reproduza, pela sua forma, os traços essenciais da atividade encarnada, acumulada no objeto".

Para isso, a mediação social é condição essencial, pois, conforme o autor:

As aquisiçóes do desenvolvimento histórico das aptidóes humanas não são simplesmente dadas aos homens nos objetos da cultural material e espiritual que os encarnam, mas são aí apenas postas. Para se apropriar destes resultados, para fazer deles as suas aptidóes, "os órgãos da sua individualidade", a criança, o ser humano, deve entrar em relação com os fenômenos do mundo circundante através doutros homens, isto é, num processo de comunicação com eles. Assim, a criança aprende a atividade adequada. (LEONTIEV, 1978, p. 272, grifos do autor).

Assumir, então, essa compreensão histórico-cultural do processo de humanização implica compreender a essencialidade da educação, isto é, de todas as experiências vividas pela criança no seio da cultura e mediadas pelos outros para a 
constituição da personalidade. Implica, portanto, redimensionar o papel docente na organizaçáo do conjunto de experiências que as crianças vivem na escola de modo que a relação entre a cultura, o professor/a e a criança promova essa formação da personalidade em suas máximas possibilidades.

A organização dessas experiências só é possível quando se conhece a criança que nasce dessa nova concepção de desenvolvimento humano e quando se compreende a especificidade das linguagens por meio das quais as crianças pequenininhas estabelecem relação com seu entorno cultural.

Partimos, agora, do pressuposto de que as funçóes psíquicas superiores se formam e se desenvolvem por meio dos processos de apropriação e objetivação, isto é, no encontro ativo da criança com a cultura mediado pelo outro. Para compreender o lugar da criança nesse processo, consideramos com Vigotski (2010) o conceito de vivência. Para o autor:

A vivência é uma unidade na qual, por um lado, de modo indivisivel, o meio, aquilo que se vivencia está representado - a vivência sempre se liga àquilo que está localizado fora da pessoa - e, por outro lado, está representado como eu vivencio isso, ou seja, todas as particularidades da personalidade e todas as particularidades do meio são apresentadas na vivência, tanto aquilo que é retirado do meio, todos os elementos que possuem relaçáo com dada personalidade, como aquilo que é retirado da personalidade, todos os traços de seu caráter, traços constitucionais que possuem relação com dado acontecimento. Desta forma, na vivência, nós sempre lidamos com a união indivisível das particularidades da personalidade e das particularidades da situação representada na vivência. (VIGOTSKI, 2010, p. 686, grifos do autor).

Desse ponto de vista, a criança é sempre ativa no processo de estabelecer relaçóes com o meio e conhecê-lo, isto é, atribuir ao que vive um sentido. Com isso, o autor contribui para superar uma polêmica presente nas discussóes acerca do protagonismo na educaçáo infantil. Entre os que defendem o protagonismo do adulto, os que defendem o protagonismo da criança, ou os que referenciam a cultura - o meio - como elemento essencial, o conceito de vivência parece deixar claro que não se trata do protagonismo nem de um nem de outro, mas da relação que se estabelece entre eles e que condiciona a aprendizagem e o desenvolvimento humano nessa etapa da vida. A criança não é, pois, um ser incapaz tal como costuma ser tratado nas escolas de educação infantil - situação denunciada por pesquisadores contemporâneos (SOUZA, 2007; CRUZ, 2008) e pelo próprio Vygotski (1995) quando desafia a psicologia de seu tempo 
a buscar o positivo e não o negativo no desenvolvimento infantil. Segundo o autor, "a tarefa que se estabelece hoje em dia à psicologia é a de captar a peculiaridade real da conduta da criança em toda a sua plenitude e riqueza de expansão e apresentar o positivo de sua personalidade" (VYGOTSKI, 1995, p. 141, tradução nossa).

A compreensão de que as aprendizagens promovem o processo de humanização - isto é, movem o desenvolvimento - envolve necessariamente olhar o positivo do desenvolvimento das crianças desde pequenininhas, envolve perceber a especificidade das formas de relação da criança com o mundo que a rodeia, ou seja, a linguagem por meio da qual ela estabelece relaçóes com o mundo de objetos e pessoas em seu entorno e vai atribuindo um sentido ao que vive e conhece.

Desse ponto de vista histórico-cultural, nasce uma criança capaz - e não incapaz como se pensa orientado por uma compreensão de aprendizagem como produto do desenvolvimento e não como propulsora deste. Orientar o trabalho docente no primeiro ano de vida e na primeira infância pela percepção das possibilidades é essencial para a produção de uma educação promotora de desenvolvimento, pois quando dirigidas pelo senso comum, as práticas docentes não consideram o desenvolvimento efetivo das crianças pequenas por entendê-lo inexistente (TIZARD; LEZINE apud FALK, 2010) e, tampouco, a zona de desenvolvimento próximo para onde o trabalho deve estar orientado (VIGOTSKII, 1998). A atitude que subestima as possibilidades das crianças acaba por produzir uma prática pobre por meio da qual se produz a incapacidade na qual se acredita.

Como defende Vygotski (1996), o primeiro ano de vida é marcado pela contradição entre a máxima sociabilidade da criança pequenininha e sua mínima possibilidade de comunicação (ao menos sob a forma tradicional como esta se efetiva). Isso cria na criança um desejo de comunicação, que Mújina (1990, p. 67) vai apontar como "a primeira necessidade social da criança", criada a partir da relação que estabelece com o adulto. Isso implica que a intençấo do adulto deve estar orientada para promover - que podemos entender como ensinar - essa comunicação. Seu esforço deve ter como objetivo estabelecer e manter essa comunicação com o bebê desde os primeiros dias de vida em todos os momentos de cuidado.

$\mathrm{Na}$ experiência italiana de educação infantil (RINALDI, 1999), isso se convencionou chamar de atitude de escuta - que cria e deflagra um processo em que o adulto se esforça por escutar, observar e interpretar os sinais das necessidades das crianças, suas intençôes de comunicação. No Instituto Pikler-Lóczy, como se verá, esta é a marca definitiva do cuidado e educação das crianças no primeiro ano de vida.

A comunicação emocional, segundo Mújina (1990), é a atividade que guia o desenvolvimento do bebê no primeiro ano de vida. Ela advém de uma ação em comum 
em que o adulto se esforça por estabelecer com a criança, por meio do olhar, da fala e do toque, uma interlocução em que a criança presta atenção no adulto e este presta atenção na criança. Essa relação cresce ao longo do primeiro ano, de tal modo que os objetos utilizados pelo adulto ou os objetos que aproxima do bebê vão criando nele o prazer e a necessidade de impressões (ver, ouvir, tocar).

Assim, essa comunicação emocional direta - esse relacionar-se por relacionar-se - que caracteriza o período inicial da vida do bebê se transforma em atividade conjunta do adulto e da criança. É por meio dessa comunicação emocional, sua forma essencial de relaçáo com o mundo, que a criança se apropria da linguagem e vai estabelecendo os primeiros contatos. Essa experiência possibilita a criança pequenininha ampliar o rol de objetos que insere em sua percepçáo e assim vai, paulatinamente, ampliando sua atividade, organizando e reorganizando os processos psíquicos e começa a formar os traços de sua personalidade.

Porque é "a atividade cujo desenvolvimento governa as mudanças mais importantes nos processos psíquicos e nos traços psicológicos da personalidade da criança" (LEONTIEV, 1998, p.65), a comunicaçáo emocional é a atividade que guia o desenvolvimento da criança nos primeiros meses de sua vida, E, ainda que do ponto de vista da estrutura da atividade, não se possa dizer que a criança seja consciente da relaçáo necessidade/objeto/motivo/objetivo, é possível observar que ela se encontra inteiramente envolvida na comunicação e que "um tipo especial de experiências psíquicas - emoçôes e sentimentos”- a envolve (LEONTIEV, 1998, p.68).

Vamos percebendo, a partir dos estudos da teoria histórico-cultural, que, seja no primeiro ano de vida, seja na primeira infância, seja considerando outras idades, o processo de produçáo da personalidade (REPKIN, 2014) - a constituição das funções psíquicas superiores - resulta sempre da agência da criança, da condição em que ela ocupa o lugar de sujeito na relaçáo com o mundo. Retomando Vigotski (2010), a influência do meio sobre o desenvolvimento da criança só pode ser compreendido e dimensionado pelo prisma da relação que a própria criança estabelece com esse meio.

Em outras palavras, a criança que se relaciona com o mundo desde os primeiros dias de vida e vai se apropriando dele, atribuindo um sentido ao que sente - às experiências vividas -, ampliando sua apropriação e provocando seu próprio desenvolvimento, é sujeito na relação.

No entanto, como vimos acima, as relações das crianças com o mundo são mediadas socialmente, em geral, ainda que não exclusivamente, pelas geraçôes mais velhas. $\mathrm{Na}$ escola de educação infantil de zero a três anos, essa relaçáo é mediada, em última instância, pelo/a professor/a, pelas pessoas adultas que cuidam e educam as crianças. 
A qualidade dessa relação envolve uma concepção de criança capaz de se relacionarcom os objetos e com as pessoas, o que, por sua vez, resulta do conhecimento das crianças, das regularidades de seu desenvolvimento - isto é, do processo como as sensações vão informando a percepção que vai se tornando categorial ao mesmo tempo que vai formando a memória que subsidia a apropriação da fala e, esta, portanto, vai criando as condiçôes para o pensamento verbal que promoverá um salto qualitativo no desenvolvimento de todas as funçôes psíquicas na criança.

Com isso, será igualmente fundamental o reconhecimento das atividades que guiam o desenvolvimento nessa idade - a comunicação emocional que, por meio da atividade conjunta do adulto com a criança, cria as bases para a atividade com objetos. Ainda, para dimensionar e intencionalmente organizar a influência do adulto, o conhecimento de estudos e pesquisas envolvendo crianças na primeiríssima e primeira infância é fundamental. Compreender que a influência educativa é mais efetiva se considera o momento em que determinada função está se formando - não antes de se formar e nem depois de formada (VYGOTSKI, 1996) - ajuda o professor a dirigir seu trabalho para as funçôes em processo de formação superando a pressa que tem imposto às crianças um abreviamento de sua infância.

Distinguir o desenvolvimento funcional do desenvolvimento evolutivo (ZAPOROZHETS, 1987) ajuda a fazer escolhas do que propor para as crianças para ampliar seu rol de açôes. O primeiro se dá na formação de capacidades isoladas que levam a mudanças pontuais que não produzem transformaçôes significativas no desenvolvimento geral da personalidade, ou seja, não levam a um novo nível de compreensão da realidade, nem a um nível mais elevado de objetivação da criança. $\mathrm{O}$ desenvolvimento geral ou evolutivo envolve a reestruturação do sistema de relaçóes da criança com as pessoas que a rodeiam e a passagem a novos níveis de atividade, ou seja, permite a formaçáo de novos níveis de compreensão da realidade e acarreta transformaçôes significativas na personalidade. Essas transformaçóes, possíveis pelas novas estruturas psicológicas, isto é, os novos planos de reflexo da realidade que vão se formando na infância, têm lugar na atividade (LEONTIEV, 1998; PODDIÁKOV, 1987; VÉNGUER; VÉNGUER, 1993).

Da mesma forma, superar a percepção das etapas da vida da criança como produto da idade cronológica e adotar a situaçáo social de desenvolvimento como um indicador dos níveis efetivo e próximo de desenvolvimento da criança, permite ao/à professor/a coloca-se o desafio de organizar situaçóes e ambientes promotores do crescimento cultural e intelectual das crianças.

Compreender que à medida que a criança avança em seu desenvolvimento, vai rompendo com comportamentos anteriores e inaugurando novas formas de relaçáo 
com o entorno, com os outros e consigo mesma é elemento essencial na superação da tensão desses momentos de ruptura que vive a criança ao passar de uma idade a outra, quando passa a adotar uma nova linguagem de comunicaçáo com o mundo que a rodeia.

Segundo Leontiev (1998), as crises de comportamento percebidas pela psicologia tradicional denunciam a ausência de intencionalidade dos adultos informada pelo conhecimento do processo de desenvolvimento infantil. Para o autor, se o desenvolvimento psíquico da criança não encontrar no adulto uma atitude espontaneísta, mas for um processo intencionalmente acompanhado, crises não ocorrerão. E a própria mudança de um estágio de desenvolvimento para outro, segundo Leontiev (1998, p.67): “Corresponde a uma necessidade que está surgindo, e ocorre em conexão com o fato de a criança estar enfrentando a educação com novas tarefas correspondentes a suas potencialidades em mudança e a uma nova percepção".

Perceber, pois, o complexo movimento que envolve a criança em seu processo de humanização é condição necessária para o/a professor/a organizar situações que possibilitem o desenvolvimento infantil, o que implica promover o acesso das crianças à cultura sem retirar delas o protagonismo na atividade, uma vez que como se aprende com a afirmação acima, a criança precisa de espaço para crescer e este é fruto da intenção do adulto orientada por uma perspectiva de educação desenvolvente (DAVYDOV, 1988). Sendo assim, como fazer isso com crianças entre 0 e 3 anos?

\section{A criança pequenininha como sujeito da comunicação emocional}

No Instituto Pikler-Lóczy de Budapeste, no contexto específico de uma instituição destinada à crianças órfấs, o trabalho pedagógico fundamenta-se na ideia de que nada pode ser deixado ao improviso dos adultos nem determinado por suas necessidades e comodidades. Tudo deve ser organizado, planejado, realizado e avaliado com o único objetivo de criar as condiçóes favoráveis ao desenvolvimento harmonioso das crianças no interior do grupo, superando a situação ainda típica de muitas creches e instituiçóes que acolhem crianças de zero a seis anos em que são tratadas não como sujeitos em processo educativo, mas como objeto de trabalho dos adultos.

O trabalho iniciado por Emmi Pikler nos anos 1940, e que segue até os dias atuais, orienta-se para a formação da condição humana das crianças pequenas como sujeitos de emoçôes, de movimentos, de interaçôes, de exploração do mundo que se apresenta ao seu alcance, demonstrando que é possível "mesmo no interior de uma instituição [...] criar as condiçóes para que os bebês e as crianças pequenas se 
desenvolvam favoravelmente, tanto do ponto de vista físico como psíquico" (FALK, 2004, p.16-17).

Com base na investigação fundamentada na observação natural da vida dos bebês, acompanhada de estudos bibliográficos de trabalhos realizados em outros países sobre os processos evolutivos da criança pequena e de suas implicaçóes para as práticas diárias de cuidado e educação, o trabalho pedagógico realizado pelo Instituto PiklerLóczy supera as condiçôes a que as crianças órfẫs são muitas vezes submetidas nas Instituições que as acolhem, onde os adultos estabelecem com elas uma relação de indiferença, com pouco diálogo, muitas proibições (LEZINE apud FALK, 2004), utilizando-se de movimentos rápidos, mecânicos e silenciosos em situaçôes de cuidado e higienização, sem observar as necessidades e iniciativas das crianças (TIZARD apud FALK, 2004).

Os princípios propostos à equipe de profissionais do Instituto Pikler-Lóczy, considerados como unidade indissolúvel que determina a organizaçáo de todo o trabalho educacional, defendem a comunicação essencial entre adultos e criança por meio da relação afetiva privilegiada e a importância da forma e do conteúdo dessa relação; a valorização da atividade autônoma da criança; a necessidade de promover na criança a tomada de consciência de si e do meio; e a importância de um bom estado de saúde física, base para a aplicação dos princípios precedentes e também seu resultado (DAVID; APPELL, 2012).

Considerado o objetivo deste artigo, vamos nos deter mais especificamente na comunicação entre adulto e criança e na atividade autônoma da criança. Interessante observar que tais princípios, definidos na década de 1940 para promover mudanças no sistema de cuidado e educação das crianças pequenininhas para uma realidade geograficamente distante do Brasil, representam o desafio a ser enfrentado hoje para a educação das crianças pequenas no sistema educacional brasileiro, onde muitos/as professores/as com formação no curso de pedagogia se recusam a assumir atividades de cuidado com as crianças pequenininhas e deixam para auxiliares - em geral profissionais sem formação específica - esse momento privilegiado da relação individualizada entre adulto e criança.

\section{A comunicação emocional entre adulto e criança}

No Instituto Pikler-Lóczy, o cuidado de qualidade às crianças pequenininhas é entendido como satisfaçáo também das necessidades afetivas e da atividade da criança. Considera-se que a criança chega a conhecer seu corpo por meio daquilo que ela mesma é capaz de fazer com o corpo e por meio daquilo que os outros fazem a seu corpo quando 
a lavam, a trocam, a alimentam, enfim, quando cuidam dela e nesse processo a educam. Por isso, um dos princípios fundamentais que orientam a prática pedagógica dos profissionais é a relação de afeto - no sentido de ser afetado por, deixar-se afetar por estabelecida entre o adulto e a criança, o que envolve o esforço do adulto para se comunicar com a criança de maneira carinhosa e respeitosa ao falar, tocar, pegar, alimentar e trocar a criança.

Durante o primeiro ano, "os momentos mais importantes da interação adulto/criança são os de cuidados corporais" (FALK, 2010, p. 16, tradução nossa), pois são a oportunidade da criança ter a atenção do adulto dirigida somente para ela, o que, por um lado, permite ao educador conhecer as necessidades da criança para melhor atendê-la, por outro lado, possibilita a segurança afetiva que permite que a criança aproveite profundamente os momentos de atividade livre e exploração do seu entorno que se intercalam com os momentos de cuidado -sem precisar da atençấo diretiva dos adultos (FALK, 2013).

A intencionalidade característica dos momentos de relação individualizada com a criança orienta o adulto a utilizar um tom de voz baixo e gestos suaves, tornando a relação um momento de prazer para a criança e para o adulto e não uma "uma fonte de angústia e insegurança” (FALK, 2010, p. 20, tradução nossa) para a criança - o que acontece quando ela náo é capaz de prever o que se passará com ela - e fonte de estresse para o adulto, que, sem perceber o processo educativo como indissociável do cuidado, busca apenas se desincumbir da tarefa de cuidar.

Por isso, entendendo que cuidar e educar são parte do mesmo ato, um dos princípios fundamentais que orientam a prática pedagógica dos profissionais é a relação afetiva privilegiada entre um mesmo adulto e a criança, o que envolve manter uma pessoa de referência para os momentos de cuidado com o objetivo de promover uma relação afetiva estável e duradoura. Isso significa que para cada grupo de crianças há sempre uma mesma educadora responsável diariamente pelo banho, troca e alimentação das crianças. Também por isso, os momentos de cuidado exigem tempo de dedicaçáo do adulto a cada criança, de modo que ela possa participar dos acontecimentos que a afetam - momentos de atenção diária que buscam seu bem estar e seu conforto -, realizando movimentos que já é capaz de fazer e sendo estimulada pelo adulto a realizar outros que ainda estáo em processo de desenvolvimento.

A regularidade dos acontecimentos no tempo e a estabilidade das situaçóes de cuidado e de atividade autônoma num ambiente preparado para provocar a atividade das crianças pequenininhas criam uma constância nas atitudes educativas e, assim, contribuem para favorecer a percepção da criança dos cuidados diários que recebe e do seu entorno. Dessa forma, ao perceber paulatinamente a coreografia intencional dos 
gestos dos adultos no cuidado de seu corpo, a criança pode começar a antecipar esses gestos e iniciar uma colaboração em seu próprio cuidado. $\mathrm{O}$ adulto sempre anuncia o gesto esperado da criança e espera sempre algum nível de resposta: um olhar, um movimento. De qualquer modo, nunca impóe um gesto sem a colaboração da criança. $\mathrm{O}$ respeito do adulto à personalidade da criança em formação "dita todas as suas atitudes, que procedem de uma compreensão inteligente das necessidades infantis" (DAVID; APPELL, 2012, p. 26, tradução nossa).

Assim, à delicadeza da relação do adulto com a criança "se une a preocupação constante ao apelo à participação da criança qualquer que seja sua idade" (DAVID; APPELL, 2012, p. 39, tradução nossa, grifo do autor), e, com isso, a escola infantil oferece condiçôes para que a comunicação entre o adulto - educador - e a criança se estabeleça de maneira satisfatória, especialmente nos momentos da atenção diária de cuidados, quando os adultos se esforçam por "ajudar a criança a compreender quem ela é, o que lhe acontece, o que ela faz, quem se ocupa dela, qual seu entorno, qual sua situaçáo, o que vai acontecer tanto num presente imediato como, no caso de crianças maiores, num futuro próximo"(DAVID; APPELL, 2012, p. 27, tradução nossa).

Mesmo à criança pequenininha se solicita - e se espera concedendo-lhe tempo a sua participação. Isto a ajuda a afirmar-se como pessoa como pessoa que ocupa um lugar significativo nas relaçóes sociais de que participa. E, como afirma Leontiev (1998), isso exerce uma força motora em seu desenvolvimento.

Essa comunicaçáo emocional que torna a criança pequenininha como sujeito da atividade de cuidado e educação própria do primeiro ano de vida só é possível pelo desenvolvimento da atividade autônoma com objetos pelas crianças. Esse é outro princípio fundamental do trabalho pedagógico desenvolvido no Instituto Pikler-Lóczy, cujo conhecimento contribui para o trabalho pedagógico realizado em creches hoje, dadas as semelhanças da condição de educação extra-doméstica de crianças pequenas crescente na sociedade contemporânea.

Da mesma forma que por meio da comunicação emocional se fortalece a segurança afetiva da criança - o que condiciona positivamente a formaçáo de sua personalidade -, a atividade autônoma com objetos "é também condição para que o pequeno forme uma imagem de si mesmo e de seu lugar no mundo" (FALK, 2010, p. 24, tradução nossa).

\section{Valorização da atividade autônoma}

O pressuposto que orienta a valorização da atividade livre das crianças no Instituto Pikler-Lóczy é o de que "todo ato desejado e executado ativamente pelo sujeito 
tem para este consequências imediatas e a longo prazo muito mais enriquecedoras que os atos impostos e suportados" (TARDOS; SZANTO, 2004, p. 34). Entretanto, essa descoberta ainda não impactou de fato as práticas de educação, especialmente para as crianças pequenininhas.

Como afirmam as autoras,

[...] a imagem que do recém-nascido é teimosamente fixa. O recém-nascido ainda é considerado como alguém a quem teremos de ensinar tudo, ou pelo menos, alguém a quem temos de fazer exercitar suas capacidades segundo nos pareça importante para seu desenvolvimento. Ao mesmo tempo, náo se dá suficiente importância às suas atividades, nem às suas descobertas autônomas. Muitas vezes involuntariamente e muitas vezes com bons argumentos, o adulto impede que a criança atue fora dos momentos concretos que ele - adulto tenha previsto. (TARDOS; SZANTO, 2004, p. 34).

Nos intervalos entre uma e outra atenção individual, as crianças são deixadas livres em um ambiente organizado para provocar sua atividade. A atividade autônoma que orienta a prática pedagógica do Instituto Pikler-Lóczy é considerada "algo essencial na educação de qualquer criança” (DAVID; APPELL, 2012, p. 24, tradução nossa) e náo apenas de criança educadas coletivamente, pois contribui para o desenvolvimento motor harmonioso, favorece a experimentação de situaçóes novas, o desenvolvimento do pensamento e de atitudes criativas no futuro (PIKLER, 1969), além de ser fonte de satisfação para as crianças.

Como afirma Falk (2010, p. 19, tradução nossa), “[...] convém destacar, no entanto, que a autonomia não é um fim em si mesma. Só adquire um autêntico valor se implica na alegria do 'eu faço sozinho', apenas se essa independência constitui um privilégio a que a criança dá uma grande importância”.

Não se trata, pois, da autonomia muitas vezes anunciada que exige que, mesmo antes do tempo, a criança pequena se responsabilize por cuidados de seu corpo que favorecem os adultos, mas não são percebidas pela criança como conquistas. Ao contrário, essa pseudoautonomia que resulta do abandono pode promover muito mais a insegurança e o mal estar nas crianças.

No Instituto Pikler-Lóczy, o papel do/a professor/a é de vital importância, ainda que não como fonte de estímulo direto à atividade da criança. $\mathrm{O}$ respeito à iniciativa das crianças, desde bem pequenininhas, de realizar atividades de maneira livre e espontânea sem a intervençáo direta dos adultos sobre sua atividade permite que a criança assuma o papel de sujeito da atividade, que siga um processo de manuseio e aproximação com os 
objetos que chamam sua atenção. Isso é bastante diferente do sistema de relaçôes em geral presente em escolas e instituiçóes que acolhem crianças em que "o adulto intervém com a ajuda e com o 'ensino', mas também com limitações e com proibições" (PIKLER, 1969, p. 129).

Segundo Pikler (1969, p. 14), no Instituto, o adulto não intervém de maneira direta na atividade da criança "[...] nem para distraí-la, nem para ajudá-la em suas ações, nem impondo uma estimulaçáo direta ou um ensinamento que, em lugar de ajudar na atividade e na necessidade de autonomia da criança a converterão num ser passivo e dependente".

No entanto, a criança nunca é abandonada em sua atividade: “a educadora está sempre por perto e ela e a criança estão sempre num raio de escuta e visão mútuas" (DAVID;APPELL, 2012, p. 26, tradução nossa), além de se responsabilizar pela organização do ambiente e dos materiais que provoquem o tateio com objetos, a exploração do espaço, os movimentos corporais e as relaçôes com pares e adultos. Nesse aspecto, quer se trate das roupas que as crianças usam, quer se trate dos materiais disponíveis para a atividade exploratória livre das crianças, percebe-se uma atenção constante dos adultos em transformar o ambiente de acordo com a evoluçáo dos grupos de crianças para favorecer ao máximo as possibilidades de atividade, assim como sua autonomia para realizar um número cada vez maior de movimentos.

Nesse processo, os adultos não fazem pelas crianças o que cabe a elas fazer para formar suas funçôes psíquicas superiores como a percepção, a memória, a fala, o pensamento -que nas crianças pequenininhas acontece na ação; não criam dependência ou atitudes de espera, mas condiçôes para que as próprias crianças explorem o mundo ao seu redor e realizem livremente seus próprios movimentos criando as condiçóes necessárias aos próximos e mais elaborados movimentos. Fazem isso ao colocar ao alcance das crianças uma variedade de objetos que provocam sua atividade, ao organizar o ambiente e mesmo as vestimentas das crianças de modo a possibilitar sua livre movimentação, ao respeitar seu ritmo de desenvolvimento motor e reconhecer, verbalmente, os avanços obtidos por elas no decorrer do processo, ajudando-as a tomar consciência de suas conquistas.

Consideram que a não intervenção direta do adulto sobre a atividade da criança oferecendo constantemente novas fontes de interesse é uma forma de se relacionar com as crianças que, por um lado, possibilita sua atividade seguindo seus interesses imediatos e, por outro lado, permite uma atenção individualizada a outra criança nesse mesmo período.

Dessa maneira, a criança alterna, ao longo do dia, momentos de atenção individualizada de qualidade e momentos de atenção indireta entre uma e outra atividade de cuidado e atenção pessoal. 
E, dessa forma, garante-se o protagonismo do adulto como criador de mediaçóes na relação da criança pequena com o entorno, na medida em que cria as condiçóes necessárias para a realização da atividade e situaçóes em que a criança é o sujeito da atividade.

A presença de desafios como rampas e obstáculos, água e objetos como pedras, bastôes e flores na área externa, assim como bolas, pequenos recipientes, mesas baixinhas que servem de obstáculos, tecidos e objetos variados na área interna possibilitam à criança experimentar novas situaçóes e estimulam sua atividade em todos os espaços da escola desde bem pequenininhas. Conforme observação de David e Appell (2012, p. 62, tradução nossa), "aos dois meses e meio, quando já começam a adquirir um certo controle sobre suas posturas e sua motricidade manual, provam a experiência do parque".

Num estágio de desenvolvimento em que o aspecto motor é visivelmente essencial, dispensa-se uma atenção especial para a vestimenta das crianças e "desde a primeira idade evitam imobilizar a criança em qualquer posição que for” (PIKLER, 1969, p. 60).

Nesse sentido, os adultos não se ocupam em ensinar os movimentos às crianças, mas criam as condiçóes para que elas próprias os experimentem. Conforme Pikler (1969, p. 57), "no Instituto evita-se 'ensinar' ou fazer com que as crianças executem os diferentes movimentos, tampouco lhe incitam nem por ordens, nem por repetidas chamadas de atenção a que os realizem conforme nossos desejos".

Em relação à atividade independente das crianças, os adultos nunca as colocam numa posição que as crianças não sejam capazes autonomamente de alcançar e sair dela, da qual não sejam capazes de se mover com autonomia. Segundo Pikler (1969), essa atitude náo significa indiferença por parte do adulto, pois ele acompanha e deixa claro para a criança que observa e valoriza seu domínio de um novo movimento.

Segundo Golse (apud SZANTO FEDER, 2011), em nossas sociedades apressadas, as crianças pequenininhas correm o sério risco de tornarem-se prisioneiras do desejo de antecipaçáo dos adultos e de suas atitudes exigentes de eficácia e rapidez que se concretizam pelas relaçôes de poder frente às crianças.

Para o autor,

[...] renunciar a este poder supóe uma verdadeira confiança na criança, em seus ritmos de desenvolvimento (do qual depende a harmonia de suas aquisiçóes), nos benefícios da liberdade de movimento e no fato de que com uma expectativa tranquila por parte dos adultos, as diferentes aprendizagens acontecem no 
tempo certo sem que seja preciso acelerá-las de maneira equivocada. (GOLSE apud SZANTO FEDER, 2011, p. 1516 , tradução nossa).

Assim, livres das proibiçóes comumente adotadas pelos adultos em nome do cuidado às crianças pequenas, e de expectativas de aceleração do desenvolvimento, a abordagem Pikler-Lóczy da educação da primeiríssima e primeira infância, segundo Falk (2010, p. 55-56, , tradução nossa), assume que "a criança não é simplesmente o objeto de nossas atençóes e de nosso afeto, mas é o sujeito em uma situação que nos implica a ambos e que ela influencia com pleno direito os acontecimentos que lhe dizem respeito".

Da mesma forma que para a teoria histórico-cultural, no Instituto Pikler-Lóczy a mediação do adulto é fundamental para inserir a criança nas relaçóes humanas e com os objetos, para criar as condiçôes para sua atividade autônoma, fazendo-as sujeito do processo que promove seu pleno desenvolvimento.

Essa inserção, no entanto, respeita muito mais o ritmo de envolvimento das crianças que o ritmo das expectativas dos adultos. Para muitos esse pode ser um problema. No entanto, estudiosos da evolução humana descobriram que ao longo do processo evolutivo houve um gradual retardo do desenvolvimento ontogenético, ou seja, um alongamento no tempo que, nós, seres humanos levamos para nos desenvolver.

Conforme Reinach (2013), "esse desenvolvimento mais lento do sistema nervoso é um dos mecanismos que levaram nosso cérebro a ser tấo diferente do de nossos ancestrais". Nesse sentido, nossa capacidade cognitiva se desenvolve "de forma lenta e gradual e exatamente por esse motivo chegamos "mais longe" que nossos ancestrais. Se por um lado, isso permite ter um sistema cognitivo mais sofisticado, esse retardo faz com que as crianças dependam mais tempo da ajuda dos pais".

Este parece ser um forte argumento para adotarmos uma mediação docente atenta e promotora do desenvolvimento humano, mas que não atropele as regularidades do desenvolvimento infantil (MÚJINA, 1990).

\section{Considerações finais}

Sem pretender discutir aqui em profundidade a complexidade desse trabalho de ação investigativa que se desenvolve já ao longo de quase sete décadas, buscamos aproximar as práticas educativas desenvolvidas no Instituto Pikler-Lóczy e os fundamentos da teoria histórico-cultural que demonstram a necessidade de açóes educativas que contemplem a atividade principal das crianças pequenininhas - a 
comunicação emocional entre o bebê e $\mathrm{o}$ adulto e a atividade de exploração com objetos na primeira infância - para promover a formaçáo desde os primeiros anos de vida das crianças de funçôes psicológicas que possibilitarão a formação e o desenvolvimento das máximas qualidades humanas.

Nessa perspectiva, buscamos apontar práticas que, de nosso ponto de vista, constituem-se como elementos mediadores das diretrizes pedagógicas delineadas pela teoria histórico-cultural e podem contribuir para a formação e para as práticas de profissionais de educaçáo infantil, especialmente daqueles que se dedicam ao cuidado e educação das crianças até os três anos de idade, segmento que tem recebido historicamente pouca atençáo de educadores e mesmo de investigadores, por se compreenderainda a criança pequenininha como incapaz de interaçóes e envolvimentos mais complexos.

As práticas desenvolvidas pelo Instituto Pikler-Lóczy mereceriam uma descrição detalhada para explicitar a complexa tessitura com a qual se organiza diariamente a vida da criança, a confiança e o respeito mútuos que constituem a essência da relação colaborativa - da efetiva comunicação - que se estabelece entre adulto e criança, o desenvolvimento do movimento livre e a atividade com objetos, assim como aprofundar a discussáo sobre o lugar do adulto e o modo como este investe no bem estar e no desenvolvimento de cada criança.

Parece-nos adequado destacar aqui que, ao buscar compreender as implicaçóes da teoria histórico-cultural para a educação das crianças pequenas, temos formulado diretrizes para a organização do espaço, a gestão do tempo, a articulação das relações adulto/criança e para a proposição de atividades na escola da infância (MELLO, 1999, 2006, 2007, 2010; SINGULANI, 2009).

A proposição de práticas que concretizem essas diretrizes resulta de um processo de construção que toma como pano de fundo a crítica aos procedimentos vigentes na educação das crianças pequenas e a aproximaçáo com práticas de outras regióes do mundo que contribuem para essa construção - mesmo que sem uma fundamentaçáo teórica explícita coincidente com a teoria histórico-cultural (BONDIOLI; MANTOVANI, 1998; GOLDSCHMIED; JACKSON, 2006; SINCLAIR et al., 2012; MAJEM; ÒDENA, 2010).

Desse ponto de vista, a aproximação com a abordagem Pikler-Lóczy nos parece um grande ganho, não apenas para orientar a educação das crianças pequenininhas na família, mas mais especificamente nas creches quando a presença de um grupo de pequenininhos sob o cuidado de um/a professor/a muitas vezes resulta em dificuldade de articulação de um trabalho que congregue cuidado de qualidade e organização de situaçôes em que as crianças possam, dada a segurança afetiva criada nos momentos de 
cuidado, ser livres para explorar o mundo ao redor e ampliar cada vez mais suas possibilidades de movimento.

Entendemos que práticas assim organizadas, que privilegiam o protagonismo adulto e o infantil, numa relação de respeito e conhecimentos mútuos constituem as melhores condiçóes para formar e desenvolver o maior bem dos seres humanos - e que deve ser o maior objetivo da educação escolar: a personalidade e a inteligência das novas gerações.

\section{REFERÊNCIAS}

BONDIOLI, Anna; MANTOVANI, Susana. Manual de Educação Infantil de 0 a 3 anos. Tradução de Rosana Severino Di Leone e Alba Olmi. 9. ed. Porto Alegre: Artmed, 1998.

CRUZ, Silvia Helena Vieira. Fala menino! O cotidiano da creche comunitária na perspectiva da criança. In: CRUZ, Silvia Helena Vieira. (Org). A criança fala: a escuta de crianças em pesquisas. São Paulo: Cortez, 2008.p. 298-300.

DAVID, Myriam; APPELL, Geneviève. Lóczy, una insólita atención personal. Tradução de Magalí Sirera Manchado. Barcelona: Ediciones Octaedro, 2012.

DAVYDOV, Vasilii. La enseñanza escolar y el desarrollo psíquico. Tradução de Marta Shuare. Moscou: Editorial Progresso, 1988.

FALK, Judit. Educar os três primeiros anos: a experiência de Lóczy. Tradução de Suely Amaral Mello. Araraquara, SP: JM Editora, 2004.

FALK, Judit. Lóczy, educación infantil. 2. ed. Barcelona: Octaedro- Rosa Sensat, 2010.

FALK, Judit. Bañando el bebé. Budapeste: Asciación Pikler-Loczy de Hungria, 2013.

GOLDSCHMIED, Elinor; JACKSON, Sonia. Educação de 0 a 3 anos: o atendimento em creches. Tradução de Marlon Xavier. Porto Alegre: Artmed, 2006.

LEONTIEV, Alexis Nikolaevich. $O$ desenvolvimento do psiquismo. Tradução de Manuel Dias Duarte. 3. ed. Lisboa: Horizonte Universitário, 1978.

LEONTIEV, Alexis Nikolaevich. Uma contribuição à Teoria do Desenvolvimento Infantil. In: VIGOSTSKII, Lev Semenovich; LURIA,Alexander Romanovich; LEONTIEV, Alexis N. Linguagem, desenvolvimento e aprendizagem. Tradução de Maria da Pena Villalobos. São Paulo: Ícone, 1998.p. 59-84. 
MAJEM, Tere; ÒDENA, Pepa. Descobrir brincando. Tradução de Suely Amaral Mello e Maria Carmem Silva Barbosa. Campinas: Autores Associados, 2010. MARX, Karl. Manuscritos Econômicos e Filosóficos. São Paulo: Boitempo, 2004. MELLO, Suely Amaral. Algumas implicaçóes pedagógicas da Escola de Vigotski para a Educação Infantil. Pro-posiçôes, Campinas, SP, v. 10, n.1, p. 16-27, mar. 1999.

MELLO, Suely Amaral. Contribuiçôes de Vigotski para a escola atual. In: MENDONÇA, Sueli Guadelupe de Lima; MILLER, Stela(Org.). Vigotski e a escola atual: fundamentos teóricos e implicações pedagógicas. Araraquara, SP: Junqueira \& Marin, 2006.p. 193-202.

MELLO, Suely Amaral. Infância e humanização: algumas consideraçóes na perspectiva histórico-cultural. Perspectiva, Florianópolis, SC, v. 25, n.1, p. 83-104, jan./jul. 2007.

MELLO, Suely Amaral. A questão do meio na pedologia e suas implicaçóes pedagógicas. Psicologia USP, São Paulo, v. 21, n. 4, p. 727-739, 2010.

MÚJINA, Valeria.Psicología de la edad preescolar.Madrid: Visor, 1990.

PIKLER, Emmi. Moverse em Liberdad: desarrollo de la motricidad global. Tradução de Guilhermo Solana. Madrid: Narcea, 1969.

PINO, Angel. As marcas do humano: às origens da constituição cultural da criança na perspectiva de Lev. S. Vigotski. São Paulo: Cortez, 2005.

PODDIÁKOV, N. Sobre el problema del desarrollo del pensamiento en los preescolares. In: DAVIDOV, Vasilii; SHUARE Marta. A psicologia evolutiva y pedagógica em la URSS: antologia. Moscú: Editorial Progreso, 1987.

REPKIN, V. V. Ensino desenvolvente e a atividade de estudo. Ensino Em Re-Vista, Uberlândia, v. 21, n. 1, p. 85-99, jan./jun. 2014.

REINACH, Fernando. Neotonia e educação infantil. Estado de São Paulo, São Paulo, 25 maio 2013.

RINALDI, Carla. A Escuta Visível.Boletim ReggioChildren, ReggioEmilia, 1999.

SINCLAIR, Hermine et al. Os bebês e as coisas. Tradução de Suely Amaral Mello. Campinas: Autores Associados, 2012.

SZANTO FEDER, Agnés. Una mirada adulta sobre el niño em acción: el sentido del movimiento en la proto infancia. Buenos Aires: Ediciones cinco, 2011. 
SINGULANI, Renata Aparecida Dezo. As crianças gostam de "tudo-o-que-não-pode": crianças em novas relaçôes com a monitora e a cultura no espaço da creche. 2009. Dissertação (Mestrado em Educação) Universidade Estadual Paulista, Marília, SP, 2009.

SOUZA, Maria Cecília Braz Ribeiro de. A concepção de criança para o enfoque histórico-cultural. 2007. Tese (Doutorado em Educação) - Universidade Estadual Paulista, Marília, SP, 2007.

TARDOS, Anna; SZANTO, Agnés. O que é autonomia na primeira infância? In: FALK, Judit (Org.).mEducar os três primeiros anos: a experiência de Lóczy. Tradução de Suely Amaral Mello. Araraquara, SP: JM Editora, 2004. p. 33-46.

VÉNGUER, Leonid; VÉNGUER, Alexander. Actividades inteligentes. Madrid: Visor Distribuiciones, 1993.

VYGOTSKI. Lev Semenovitch. Obras Escogidas III. Madrid: Visor Distribuiciones, 1995.

VYGOTSKI. Lev Semenovitch. Obras escogidas IV: Madrid: Visor Distribuiciones, 1996.

VIGOTSKII. Lev Semenovitch. Aprendizagem e Desenvolvimento Intelectual na Idade Escolar. In: VIGOTSKII, Lev Semenovitch; LURIA, Alexander Romanovich; LEONTIEV. Alexis Nikolaevich. Linguagem, desenvolvimento e aprendizagem. Tradução de Maria da Pena Villalobos. São Paulo: Ícone, 1998. p. 103-118.

VIGOTSKI, Lev Semenovitch. Quarta aula: a questão do meio na pedologia. Tradução de Márcia Pileggi Vinha. Psicologia USP, São Paulo, v. 21, n. 4, p. 681701, 2010.

ZAPORÓZHETS, Aleksander. Importancia de los períodos iniciales de la vida em la formacion de la personalidad infantil. In: DAVIDOV, Vasilii; SHUARE Marta. $A$ psicologia evolutiva y pedagógica em la URSS: antologia. Moscú: Progreso, 1987.p. 228-249. 


\section{The Pikler-Loczy approach and the cultural-historical perspective: the little child as a subject in relations}

\section{Abstract}

The understanding that human development proceeds from life experiences and education leads us to seek ways to promote this development. As we study the culturalhistorical theory, we realize the complexity of this process that involves the formation of human personality beginning from the first contacts of the child with the world around. At the same time, professionals and researchers on early childhood education seek to understand how this process takes place when children are still very little. It can be seen in cultural historical theory a set of guidelines for producing a new practice with small children who, in general, assume the role of objects of adults' work and not of personalities being formed by experiences they live. When we consider the characteristics of the practices that can arise from these theoretical guidelines, we think of the Pikler-Loczy Institute educational work and consider that its practices may mediate the culturalhistorical theory guidelines. That's what this article is all about. With it we seek an approach between the educational practices of the Pikler-Loczy Institute for toddlers developed in Hungary since the 1940s and the theory developed by Vygotsky and his collaborators around the 1920s, in the then Soviet Union. Our perspective is to seek mediations which help implement the theory, so that the socio-historical approach to human development can take place starting in early childhood education.

Keywords: Early Childhood Education. Theory-practice relation. Socio-CulturalHistorical Theory.

\section{El enfoque Pikler-Loczy y la perspectiva histórico-cultural: el niño pequeño como sujeto en las relaciones}

\section{Resumen}

La comprensión de que el desarrollo humano procede de las experiencias de vida y educación nos lleva a buscar formas de promover este desarrollo. Al estudiar la teoría histórico-cultural, nos damos cuenta de la complejidad de este proceso que consiste en la formación de la personalidad humana desde los primeros contactos del niño con el mundo que lo rodea. Al mismo tiempo, como profesionales e investigadores en educación de la primera infancia, tratamos de comprender cómo este proceso se lleva a cabo mientras los niños son todavía muy pequeños. Percibimos la teoría histórico-cultural como un conjunto de directrices que orientan nuevas prácticas educativas con los más pequeños que, en general, sin que se comprenda la complejidad de este proceso, son tratados como objetos de trabajo de los adultos y no como sujetos que se forman por sus vivencias. Cuando consideramos las características de las prácticas que pueden surgir de estas directrices teóricas, pensamos en el trabajo del Instituto Pikler-Loczy y consideramos que sus prácticas pueden mediar la aplicación de las directrices de la teoría histórico-cultural. De eso trata este artículo. Con él se busca un acercamiento entre las prácticas educativas de niños criadas en ese Instituto de Hungría desde la década de 1940 y la teoría desarrollada por Vygotsky y sus colaboradores en la década de 1920, en la entonces Unión Soviética. Nuestra perspectiva es buscar mediadores que contribuyan a que la apropiación del enfoque histórico-social para el desarrollo humano se lleve a cabo desde la educación de los más pequeños.

Palabras claves: Educación de la Primera Infancia. Relación teoría-práctica. Teoría histórico-cultural socio. 
Suely Amaral Mello

E-mail: suepedro@terra.com.br

Renata Aparecida Dezo Singulani

E-mail: resingulani@gmail.com

Recebido em: 24/4/2014 Aprovado em: 8/8/2014 